\title{
Evaluating Effect of Nitric Oxide Synthase Inhibitors on Adipocyte Formation
}

\author{
Titilayo O.E ${ }^{1}$, Eluwole O.O ${ }^{1}$, Esan A. J ${ }^{2}$ O, Omisakin C.T ${ }^{2}$ \\ Department Of Medicalmedical Laboratory Sciences, Acheiver's University Owo, Ondo State ${ }^{l}$ \\ Department Of Haematology And Blood Transfusion Science, Federal Medical Centre, P.M.B.201, Ido-Ekiti \\ Ekiti State $^{2}$
}

\begin{abstract}
:
Background: Adipose tissue can be defined as secretory cells and contains Adipocytes. Conversion of precursor cells to mature fat cells during the formation of adipocytes is controlled by transcription factors including peroxisome proliferator-activated receptor $\gamma(P P A R \gamma)$ and CCAAT/enhancer-binding protein family $(C / E B P \alpha, \beta$ and $\delta)$. Nitric Oxide is synthesized from l-arginine by one of three nitric oxide synthases (NOS). Fat mass can be reduced by dietary supplementation with l-arginine. Inhibitors of nitric oxide are classified as endogenous and synthetic. The effect of nitric oxide inhibitors on adipogenesis was investigated in cultured Murine preadipocyte cell line 7F2 derived from mouse white adipose tissue.

Methods: Murine preadipocyte cell line $7 F 2$, are maintained in DMEM culture media containing $10 \%$ FCS. Induction media contains Insulin $10 \mathrm{ug} / \mathrm{ul}$, dexamethasome $1 \mathrm{uM}$, isobutylmethylxanthine $0.5 \mathrm{mM}$ and indomethasone $100 \mathrm{uM}$, media was changed every 3days. Culture cells treated with panels of nitric oxide inhibitors was stained with Oil red $O$ working solution, and Griess assay was performed on the culture media in other to quantify the nitrate/nitrite level.

Results: 7f2 cells have measurable oil red $O$ staining after 7 days, amount of Nitric oxide secreted can be reduced by modest amounts of nitric oxide synthase inhibitors and Oil red $O$ staining is reduced by nitric oxide synthase inhibitors.
\end{abstract}

Conclusion: Role of NOS inhibitors in adipose cells proliferation and differentiation may provide new insights into treatment of obesity and control of adiposity.

Key Word: Adiposity, Nitric Oxide, Obesity

Abbreviations: BAT- brown adipose tissue, WAT- white adipose tissue, PPARy-peroxisome proliferatoractivated receptor, C/EBP $\alpha$-CCAAT/enhancer-binding protein family NO-nitric oxide, INOS- induce nitric oxide synthase, L-NMMA- N-monomethyl-arginine and N, ADMA-N-dimethyl arginine, L-NIO-N-iminoethyl-Lornithine, L-NAME-NO-nitro-L-arginine methyl ester, FCS-Fetal calf serum, NOS- nitric oxide synthase, eNOSendothelial nitric oxide synthase, nNOS- neuronal nitric oxide synthase.

\section{Introduction}

Prevalence of obesity rose slowly during the early 20th century, and it began to rise rapidly around 1980. Prevalence of children affected by obesity increased from 5\% in 1960 to $15 \%$ in 2000 (1). National Health and Nutrition Examination Survey from the 1999 to 2000 show that ' $65 \%$ and 31\% of the U.S. adult population are overweight and obese' (2). In industrialised countries, obesity is the most prevalent nutritional disorder (3). Obesity is associated with cardiovascular risk factors, type 2 diabetes mellitus, osteoarthritis and cancer (4).Balance between dietary caloric intake and whole-body energy expenditure determined fat deposition in humans or animals. Obesity in humans is as a result of imbalance in energy metabolism (5). Adipose tissue can be defined as a secretory cells and contain Adipocytes (6). It is made up of brown adipose tissue (BAT) and white adipose tissue (WAT). Increased fat cell size and triacylglycerol storage result in adipose tissue deposition in adult. Committed preadipocytes can either be inactive or active, the active committed preadipocytes generate new fat cells during the adult stage. Committed precursor cells can be stimulated when couple with appropriate intracellular signal molecules (7).Conversion of precursor cells to mature fat cells during the formation of adipocytes is control by transcription factors and numerous signalling pathways. The transcription factors that enhance adipogenesis are peroxisome proliferator-activated receptor $\gamma$ (PPAR $\gamma$ ) and CCAAT/enhancer-binding protein family $(\mathrm{C} / \mathrm{EBP} \alpha, \beta$ and $\delta)$. Peroxisome proliferator-activated receptor gamma (PPARg or PPAR- $\gamma$ ) is a member of the nuclear hormone receptor subfamily of transcription factors that served as a master regulator for adipogenesis (8). PPARg is associated with diabetes, obesity, insulin sensitivity, and dyslipidemia (9). The role of PPARg in regulating adipogenesis was established in 1998 (8).The subtypes of PPARg are involved in adipocyte differentiation and also used as antidiabetic drugs which increase peripheral insulin sensitivity. PPARg1 polypeptide is encoded by pparg1, pparg3, and pparg4 mRNAs, while PPARg2 
polypeptide is encoded by pparg2 mRNA (10). C/EBP proteins belong to basic- leucine zipper transcription factors family, with six isoforms that includes $\mathrm{C} / \mathrm{EBP} \alpha, \mathrm{C} / \mathrm{EBP} \beta, \mathrm{C} / \mathrm{EBP} \gamma, \mathrm{C} / \mathrm{EBP} \delta, \mathrm{C} / \mathrm{EBP} \varepsilon$ and $\mathrm{C} / \mathrm{EBP} \zeta(11)$. C/EBP $\alpha, \beta$ and $\delta$ s plays important roles in adipose differentiation. C/EBP $\alpha$ regulate cell-cycle exit and activates differentiation-specific genes in myeloid cells. Nitric Oxide is synthesized from 1-arginine by one of three nitric oxide synthases (NOS) (12). Nitric oxide (NO) regulates nutrient metabolism. Productions of Nitric oxide take place in all mammalian tissues and cells, examples includes adipocytes, macrophages, skeletal muscle, brain, endothelial cells, heart and hepatocytes (13). In the obese subject, modulation of the arginine-NO pathway may reduce fat mass. NOS1, NOS2, NOS3 are the human gene encoding nNOS, iNOS, and eNOS respectively. NO plays a major role in influencing fat cell formations (14). Overproduction of NO and increased expression of iNOS are associated with Obesity. In obese human, gene expression of iNOS in adipocytes was higher when compared with non-obese humans (15). Studies carried out on genetically obese and diabetic rodent models indicated that there was high expression of iNOS protein in adipose tissue and skeletal muscle compared with lean non-obese wild-types (16). Inhibitors of nitric oxide are classified as endogenous and synthetic (17). N-monomethyl-arginine (L-NMMA) and N, N-dimethyl arginine (ADMA) are classified as endogenous inhibitors of NO synthesis (18). L-NMMA was discovered in 1989 as nitric oxide inhibitor and LNMMA exerts its effect by inhibiting NOS in the vascular endothelium which generates L-citrulline from Larginine (19). N-iminoethyl-L-ornithine (L-NIO) and N0-nitro-L-arginine methyl ester (L-NAME) are referred to as synthetic analogues of arginine and are recently characterized as inhibitors of NO synthase in adrenal gland (20). The aim of the research is to evaluate effect of nitric oxide synthase inhibitors on adipocyte formation.

\section{Materals And Methods}

This research work was carried out at Department of Medical Laboratory Science, Acheiver's University Owo, Ondo State, Nigeria. The procedures and methods of the study were as follow.

\section{1) Adipocyte cell culture and differentiation}

Murine pre-adipocyte cell line 7F2, was purchased from United Kingdom Type Culture Collection and are maintained at $37^{\circ} \mathrm{c}$ and $10 \% \mathrm{CO} 2$ in Dubecco's Modified Eagle Medium (DMEM) containing 10\% Fetal calf serum (FCS) and1\% penicillin/streptomycin. Murine pre-adipocyte cell line 7F2 were seeded onto 6well plates and 24 well plates at $6 \times 10$ cells $/ \mathrm{ml}$ and incubated for $12 \mathrm{~h}$ at 37 C and $5 \% \mathrm{CO}$. Then media of each well were aspirated and fresh FBS-free DMEM media were replaced. Different concentrations of U. pumila extract (50$500 \mathrm{lg} / \mathrm{mL})$ or fractions $(20-1000 \mathrm{lg} / \mathrm{mL})$ were prepared in FBS-free DMEM to givea total volume of $500 \mathrm{lL}$ in each well of a microtiter plate.

Adiopogenesis induction media containing Insulin $10 \mathrm{ug} / \mathrm{ul}$, dexamethasome1uM, isobutylmethylxanthine $0.5 \mathrm{mM}$ and indomethasone $100 \mathrm{uM}$ was used to replace the media every 3days, for up to 15 days post-induction.

\section{2) Nitric Oxide Synthases Inhibitors}

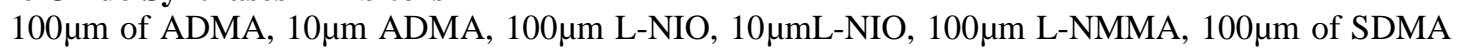
and $10 \mu \mathrm{m}$ of SMDA are used as nitric oxide synthases inhibitors and are tested on culture cell in 24 well plates.

\section{3) Oil red O Staining}

Culture cells treated with NOS inhibitors are washed with Phosphate buffered saline (PBS), fixed in 4\% Paraformaldehyde and stored at $4^{\circ} \mathrm{c}$. The cell were later washed twice with PBS and stained with Oil red O working solution which was commercially prepared, incubated at room temperature for 2 hours and visualised under the microscope

\section{4) Nitric Oxide measurement}

Griess assay was performed on the culture media in order to quantify the nitrate/nitrite level using Greiss reagent (sulfonilamide / 1-N-napthylenediamine in 1\% phosphoric acid). This was measured at $540 \mathrm{~nm}$ using Versa Max Plus Rom V1.21. 100Mm standard solution of sodium nitrite was prepared in distilled water

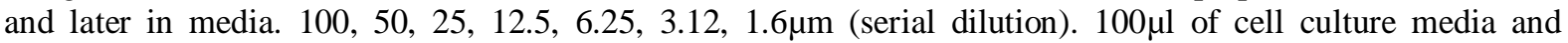
standard solutions was pipette in triplicate into each of the wells; $100 \mu \mathrm{l}$ of Griess reagent was added into each well and read at $540 \mathrm{~nm}$. Media are used as blank and negative control.

\section{5) Measurement of Oil red $O$ staining}

Oil red $\mathrm{O}$ staining was quantified by lysing the 7F2 cells in 1\% SDS, 50\% ethanol solution. Equal volume of $95 \%$ of ethanol and sodium dodiel sulphate (SDS) was added to each well containing the cell, placed on rock plate for 30min and read using Versa Max Plus Rom V1.21. 


\section{6) Statistical analysis}

The values expressed are means of three replicate determinations \pm standard deviation. Data were analyzed by ANOVA t-test. Results are expressed as means and Standard deviation.

\section{Results}

\section{1) Effect of adiopogenesis induction media on $7 \mathrm{f} 2$ cells line}

The effect of adiopogenesis induction media was measured by staining the cultured cells with Oil red $\mathrm{O}$ working solution. Plate 1a-b shows that oil red $\mathrm{O}$ can be pictured after 7 days of culture in induced cell. Figure 1a indicates that there is more of nitric oxide in the induced cell compare to the control. This implies that nitric oxide may play a major role in formation of fat cells. Figure $1 \mathrm{~b}$ shows amount of Oil red $\mathrm{O}$ staining absorbed by the control and induced cells when quantified by lysing 7F2 cells in 1\% SDS, 50\% ethanol solution and reading at $540 \mathrm{~nm}$. Calculated $\mathrm{p}$ value indicates significant difference between the control and the stimulated fat cells.

\section{2) Effect of nitric oxide synthases inhibitors on preadipocyte differentiation}

To determine the effect of inhibitors of nitric oxide synthases on preadipocyte differentiation, the culture cells were treated with NOS inhibitors and stained with Oil red O working solution. Stained cells was lysed in order to quantify oil red $\mathrm{O}$ absorbed by the fat cells. Figure $2 \mathrm{a}$ and $\mathrm{b}$ shows the effect of nitric oxide synthase inhibitors on adipogenesis. 7f2 cells have measurable oil red $\mathrm{O}$ staining after 7 days, amount of Nitric oxide secreted can be reduced by modest amounts of nitric oxide synthase inhibitors and Oil red $\mathrm{O}$ staining is reduced by nitric oxide synthase inhibitors. SDMA is not a nitric oxide inhibitors synthases so it does not have any adverse effect on adipocyte differentiation.

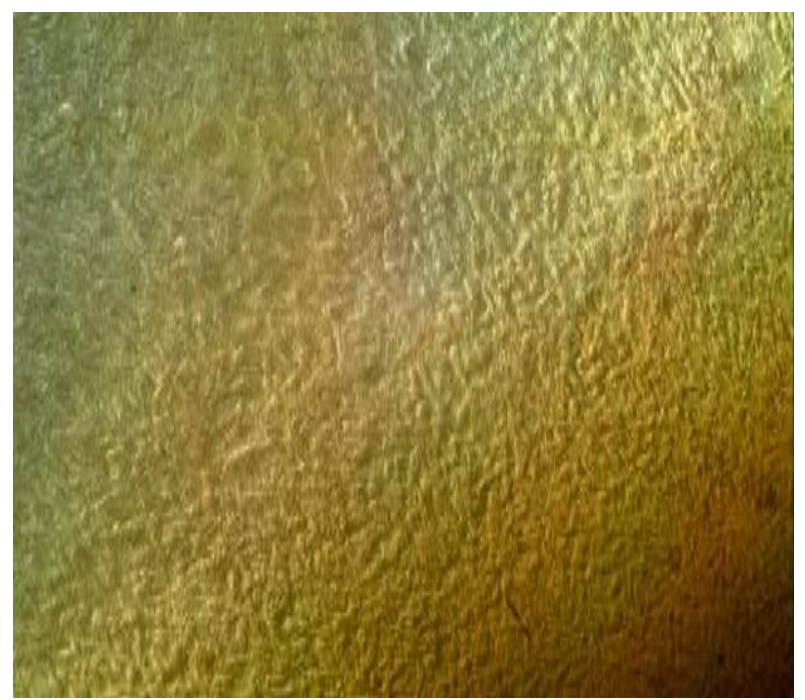

Plate (1a). Negative Control (untreated) x20

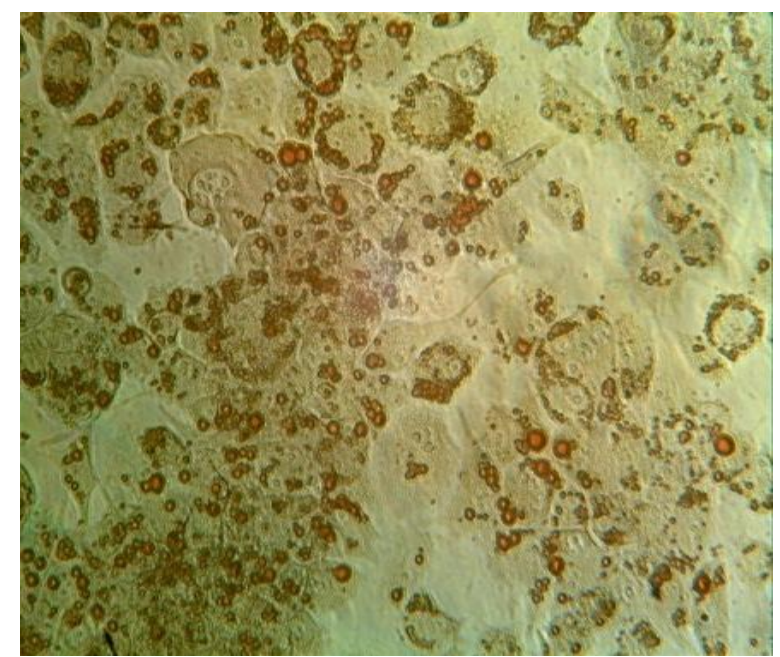

Plate (1b). Positive Control Induced x20 Oil red O staining of lipid droplets in 7F2 cells stimulated with Insulin, dexamethasome, isobutylmethylxanthine and rosiglitasone for 7 days 


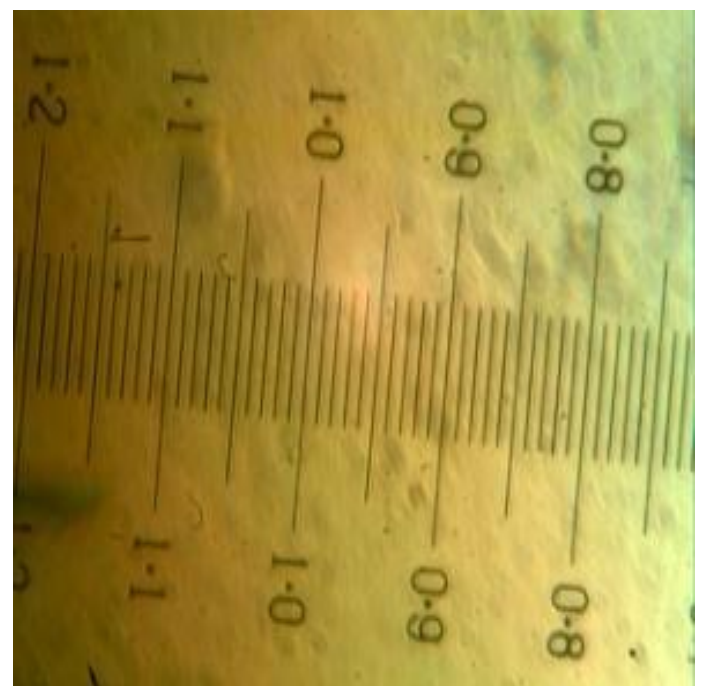

Plate 1c Measurement of the slide taken under microscope

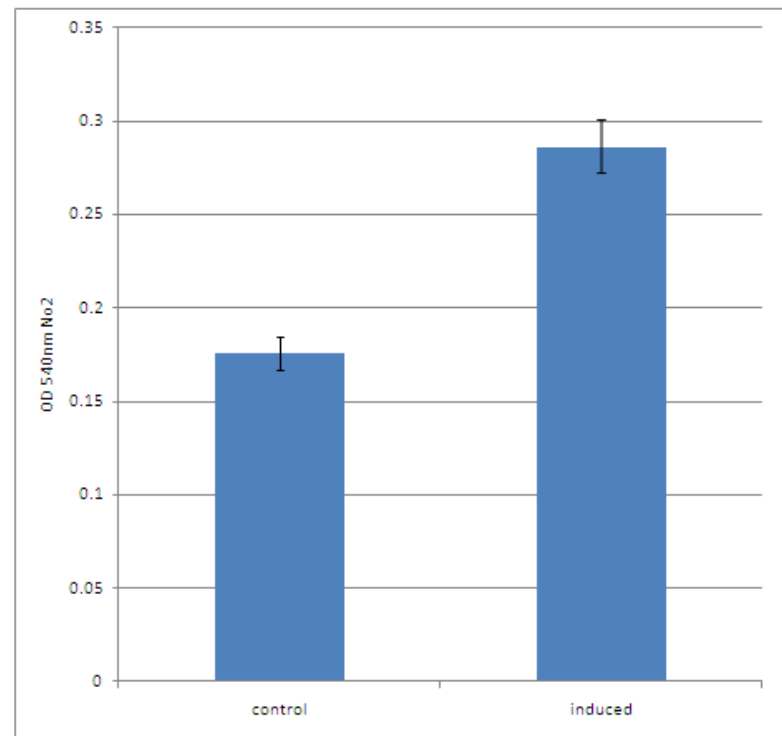

Figure 1a: Griess assay was performed on the stained cell to measure the nitric oxide present.

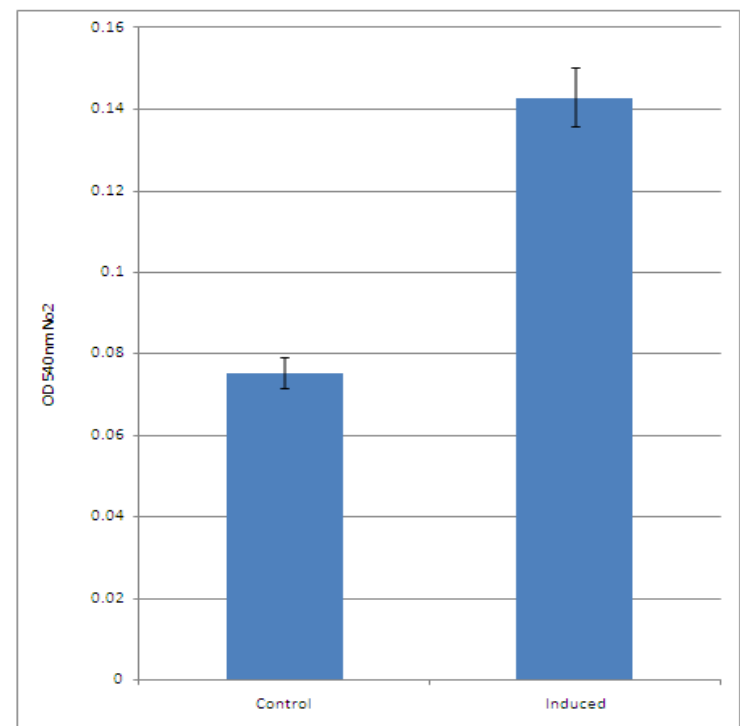

Figure (1b): Oil red O staining was quantified by lysing the 7F2 cells in 1\% SDS, $50 \%$ ethanol solution and reading at $540 \mathrm{~nm}$. 


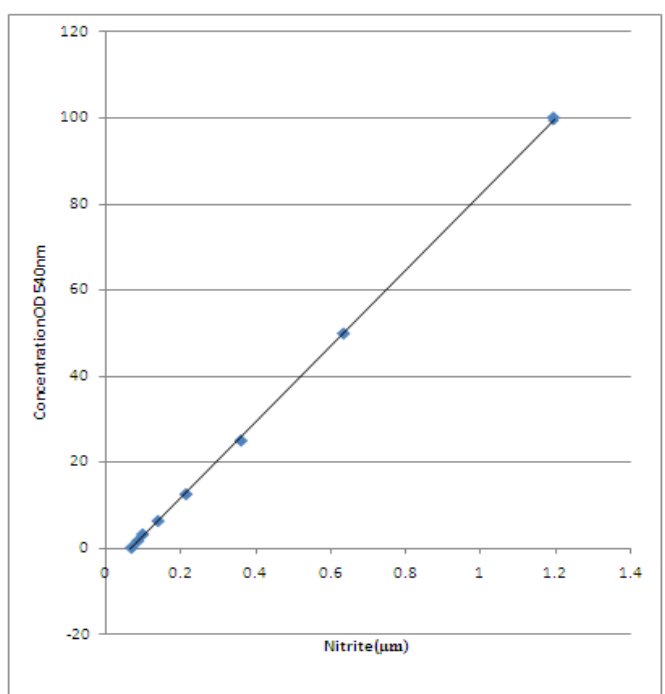

Figure (1c): Indicating high level of nitrite at higher concentration. $\mathrm{P}$ value is greater than 0.05 which indicate that there is a significant difference between the control and induced fat cell.

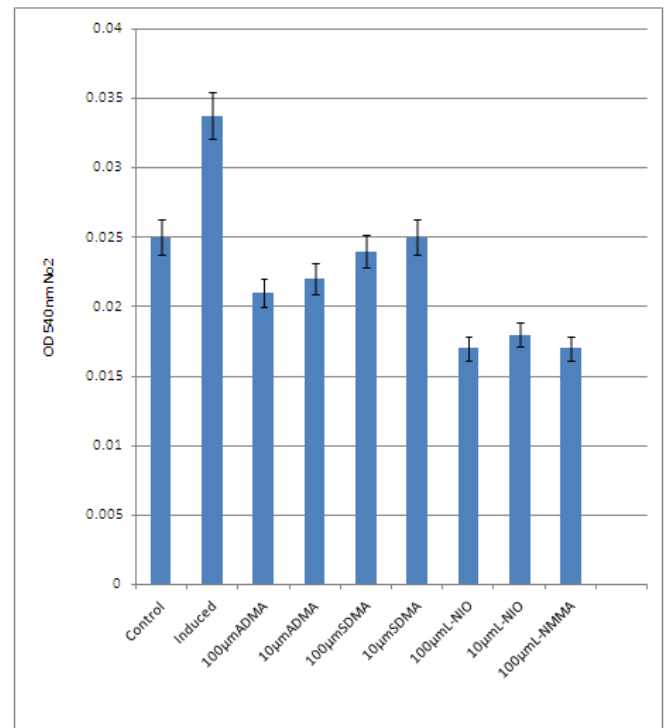

Figure 2a: Griess assay was performed on the stained cell treated with inhibitors of nitric oxide synthase in other to measure the nitrite present.

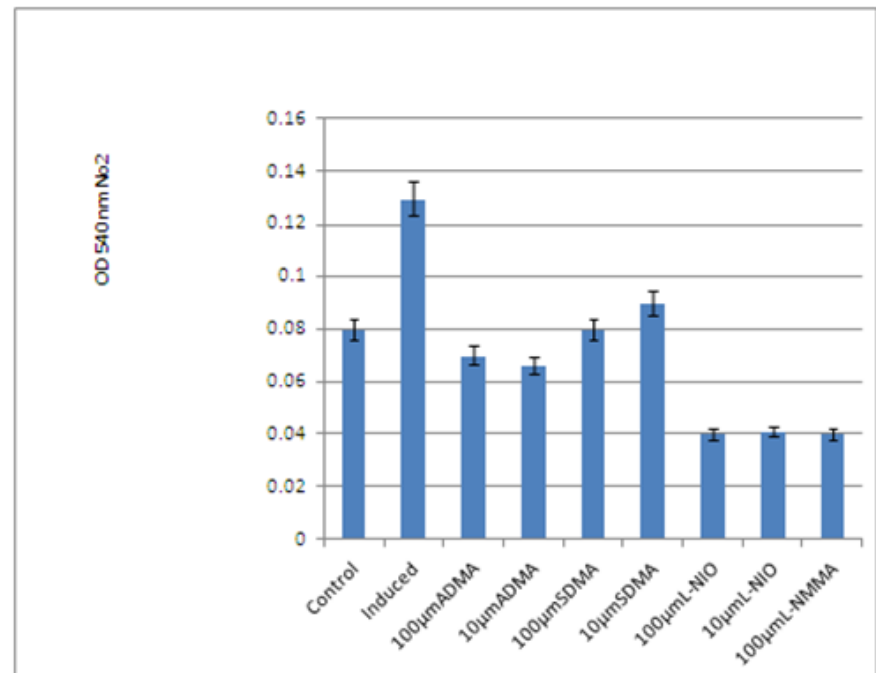

Figure 2b: Oil red $\mathrm{O}$ staining was quantified by lysing the 7F2 cells. 


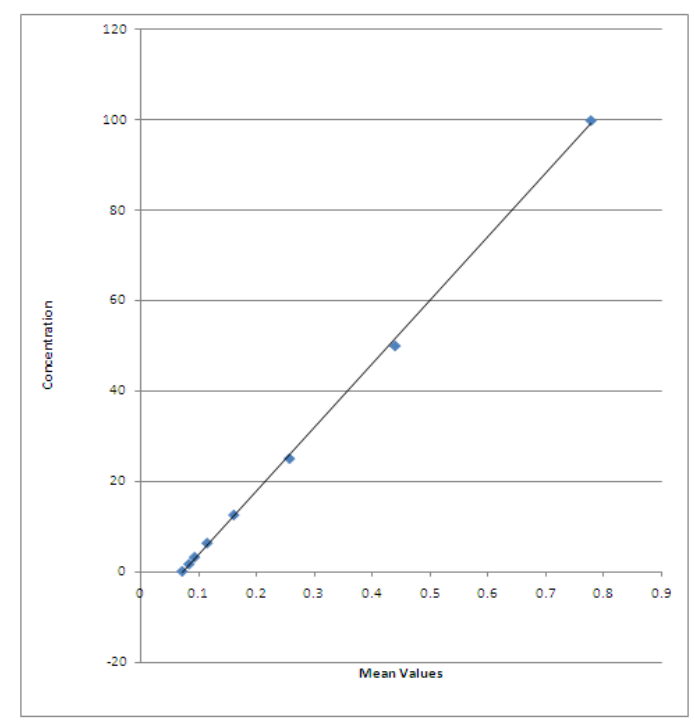

Figure 2c: Indicating high level of nitrite at higher concentration. Calculated $\mathrm{P}$ values for each of the inhibitors are greater than 0.05 which implies significant differences between Controls (untreated) and all cells treated with NOS inhibitors.

\section{Discussion}

Nitric Oxide plays a crucial role in modulating many biological functions and enhances cells proliferations and differentiations (21). Three isoforms of NOS are nNOS, iNOS and eNOS which are isolated from brain, macrophages and bovine aortic endothelial cell. NOS1, NOS2, NOS3 are the human gene encoding nNOS, iNOS, and eNOS respectively (22). White adipose tissue (WAT) expressed iNOS and eNOS and both enhance proliferation of adipose tissue (23). In 1998, Nisoli et al., reported that nitric oxide stimulates differentiation and inhibit proliferation in brown adipose cells (24). Based on the data gotten from my research, reduced nitrite level was found in fat cells treated with NOS inhibitors which may probably have an adverse effect on fat cell differentiation. The cell induced with adipogenesis stimulant show higher level of nitrite when compare to the control (None induced) suggesting that nitric oxide contribute positively to adipocyte differentiation and proliferation. Lipid droplet can be pictured after 7 days of culture when stained with Oil red $\mathrm{O}$ working solution. Further analysis was done by treating the culture cells with panel of nitric oxide inhibitors and their effect on adipogenesis was determined by greiss assay. Data gotten demonstrated that amount of Nitric oxide secreted can be reduced by modest amounts of nitric oxide synthase inhibitors. Ryden et al., 2001 discovered that the obese have increased in production of NO and expression of eNOS which influences adipose tissue mass (23). Since amount of Nitric oxide secreted can be reduced by modest amounts of nitric oxide synthase (NOS) inhibitors, further work can be carried out to known the effect of nitric oxide synthase inhibitors on gene expression of peroxisome proliferator-activated receptor $\gamma$ (PPAR $\gamma$ ) and CCAAT/enhancer-binding protein family $(\mathrm{C} / \mathrm{EBP} \alpha, \beta$, and $\delta)$ which play a major role in conversion of precursor cells to mature fat cells during the formation of adipocytes. Also the further study will also include checking the expression of iNOS and eNOS in the time dependent manner during differentiation together with adipogenesis related markers as PPARg and Fatty acid binding protein. In conclusion, the role of NOS inhibitors in adipose cells proliferation and differentiation may provide new insights into the control of adiposity and potential targets in the treatment of obesity.

\section{References}

[1]. Ogden, C.L., Flegal, K.M., Carroll, M.D., and Johnson, C.L. 2000. Prevalence and trends in overweight among US children and adolescents, 1999-2000. JAMA. 288:1728-1732

[2]. Hill, J.O., Wyatt, H.R., Reed, G.W., and Peters, J.C. 2003.Obesity and the environment: Where do we go from here? Science. 299:853-5

[3]. Kushner, R.F.2002. Medical Management of obesity. Seminars in Gastrointestinal Disease. JLR.13:123-132

[4]. Freedman, D.S., Dietz, W.H., Srinivasan, S.R., and Berenson, G.S. The relation of overweight to cardiovascular risk factors among children and adolescents: the Bogalusa Heart Study. Pediatrics. 1999;103:1175-1182

[5]. Wenjuan, S., Susan, K., Wenjiang, J., Cynthia, J., Meiningerd, G.W.2006. Regulatory role for the arginine-nitric oxide pathway inmetabolism of energy substrates. Journal of Nutritional Biochemistry. 17: 571-588

[6]. Tang, Q.Q., Gronborg, M., Huang, H., Kim, J.W., Otto, T.C., Pandey, A., and Lane, M.D. 2005. Sequential phosphorylation of CCAAT enhancer-binding protein beta by MAPK and glycogen synthase kinase 3 beta is required for adipogenesis. Proc. Natl. Acad. Sci. USA 102: 9766-9771. 
[7]. Morrison, R. F., and Farmer, S. R.2000. Hormonal signaling and transcriptional control of adipocyte differentiation. J. Nutr. 130: 3116S-3121S

[8]. Spiegelman, B.M. 1998.PPAR-g: adipogenic regulator and thiazolidinedione receptor. Diabetes.47:507-514.

[9]. Wolfrum, C., Shih, D.Q., Kuwajima, S., Norris, A.W., Kahn, C.R., and Stoffel, M. (2003). Role of Foxa-2 in adipocyte metabolism and differentiation. J. Clin. Invest. 112, 345-356.

[10]. Meirhaeghe, A., Fajas, L., Gouilleux, F., Cottel, D., Helbecque, N., Auwerx, J. and Amouyel, P. 2003. A functional polymorphism in a STAT5B site of the human PPAR gamma 3 gene promoter affects height and lipid metabolism in a French population. Arterioscler. Thromb. Vasc. Biol. 23, 289-294.

[11]. Peter, F. J. 2005. Molecular stop signs: regulation of cell-cycle arrest by C/EBP transcription factors .Journal of Cell Science.118: 2545-2555

[12]. Gunay Yetik-Anacak and John D. Catravas. 2006. Nitric oxide and the endothelium: History and impact on cardiovascular disease. 45: $268-276$

[13]. Lee, J., Ryu, H., Ferrante, R.J., Morris, S.M, Ratan, R.R.2003. Translational control of inducible nitric oxide synthase expression by arginine can explain the arginine paradox. Proc Natl Acad Sci U S A. 100:4843-4848.

[14]. Hongyun, Y., Edith, A.,Gillian, S., Wong,A., and Deena, S.2002 Nitric oxide promotes differentiation of rat white preadipocytes. JLR Papers 43: 2123-2129.

[15]. Giordano, A., Tonello, C., Bulbarelli, A., Cozzi, V., Cinti, S., and Carruba, M.O.2002. Evidence for a functional nitric oxide synthase system in brown adipocyte nucleus. FEBS Lett. 57:135-40

[16]. Fujimoto, M., Shimizu, N., Kunii, K., Martyn, J.A., Ueki, K., and Kaneki, M.A.2005. Role of iNOS in fasting hyperglycemia and impaired insulin signaling in the liver of obese diabetic mice. Diabetes. 54:1340-8.

[17]. Vallance, P., Leone,.A., Calver,.A., Collier, J. and Moncada,S.2000. Accumulation of an endogenous inhibitor of nitric oxide synthesis in chronic renal failure. Lancet. 339: 572- 575

[18]. Rainer, H., and Bo“"ger,O. 2004.Asymmetric Dimethylarginine, an Endogenous nhibitor of Nitric Oxide Synthase, Explains the "LArginine Paradox" and Acts as a Novel Cardiovascular Risk Factor1,2.J Nutr.134: 2842S-2847S.

[19]. Palmer, R. M., Ferrige, A. G. \& Moncada, S. 1987.Impotance of Nitiric oxide. Nature. 327: 524-526.

[20]. Miranda, T.B., Khusial, P., and Cook, J.R.2004. Spliceosome proteins D1, D3, and B/B_are asymmetrically dimethylated at arginine residues in the nucleus. Biochem Biophys Res Commun. 323: 382-87

[21]. Lowenstein, C. J., Dinerman, J. L., and Snyder, S. H. 1999. Nitric oxide: a physiologic messenger. Ann. Intern. Med. 120: $227-237$

[22]. Kapur, S., F., Picard, M., Perreault, Y., and Marette, A.2000. Nitric oxide: a new player in the modulation of energy metabolism.Int. J. Obes. Relat. Metab. Disord. 24: 36-40

[23]. Ryden, M., Elizalde, M., Harmelen,V.V., Ohlund,A., Hoffstedt, J., Bringman, S., and Andersson, K.2001. Increased expression of eNOS protein in omental versus subcutaneous adipose tissue in obese human subjects. Int. J. Obes. Relat. Metab. Disord 25: $811-$ 815 .

[24]. Nisoli,E., Clementi, E., Tonello, C., Sciorati, C., and Briscini, 1. 1998. Effects of nitric oxide on proliferation and differentiation of rat brown adipocytes in primary cultures. British Journal of Pharmacology 125: $888 \pm 894$ 